引用格式:马维兢,刘斌,杨德伟, 等. 基于三维生态足迹模型的流域自然资本动态评估一一以福建省九龙江流域为例 [J]. 资源 科学, 2017,39(5) : 871-880. [Ma W J, Liu B, Yang D W, et al. Dynamic evaluation of natural capital using the Three-Dimension Ecological Footprint Model: the Jiulong River Basin in Southeast China[J]. Resources Science, 2017, 39 (5) : 871-880.] DOI: 10.18402/resci.2017.05.07

\title{
基于三维生态足迹模型的流域自然资本动态评估 以福建省九龙江流域为例
}

\author{
马维咕 ${ }^{1,2,3}$, 刘 斌 ${ }^{1,2,3}$, 杨德伟 ${ }^{1,3}$, 郭青海 ${ }^{1,3}$
}

(1. 中国科学院城市环境与健康重点实验室, 中国科学院城市环境研究所, 厦门 361021 ;

2. 中国科学院大学, 北京 $100049 ; 3$. 厦门市城市代谢重点实验室,厦门 361021)

\begin{abstract}
摘 要: 自然资本评估是研究区域生态系统平衡及可持续发展的重要方法。文章基于三维生态足迹模型,核 算了 2000-2015 年九龙江流域不同地类及区域人均足迹深度、足迹广度和三维生态足迹, 并通过资本流量占用率和 存量流量利用比等指标, 详细分析了区域自然资本流量、自然资本存量的占用情况及不同地类之间的差异。结果 表明: (1)九龙江流域人均足迹深度由 2.34 增加至 4.33 , 足迹广度由 $0.463 \mathrm{hm}^{2} /$ 人增加至 $0.655 \mathrm{hm}^{2} /$ 人, 三维生态足迹由 $1.08 \mathrm{hm}^{2} /$ 人不断扩大至 $2.84 \mathrm{hm}^{2} /$ 人, 说明区域自然资本流量占用逐渐增大, 自然资本存量消耗快速上升, 生态系统资 源供给压力加剧; (2)不同地类自然资本利用差异显著,除林、草地外,其它用地从2011年开始均处于生态赤字状态; 其中, 化石能源用地需求增加最快, 是区域生态足迹加速上升的最主要原因; 3 促进九龙江流域可持续发展在于增 加资本流量限度、减少资本存量消耗, 为此需要倡导节约型消费、加大耕地资源保护力度、科学规划建设用地规模、 提高能源利用效率等。
\end{abstract}

关键词: 生态足迹; 三维模型; 自然资本; 可持续性; 九龙江流域

DOI : 10.18402/resci.2017.05.07

\section{1 引言}

为定量研究自然资本的禀赋以及评估区域经 济社会发展的可持续性, 20 世纪 80 年代专家学者 们提出自然资本核算这一概念,并进行了大量研究 ${ }^{[1-4]}$ 。 在此背景下,生态经济学家 Rees 于 1992 年提出生 态足迹的概念 ${ }^{[5]}$ 。生态足迹方法为人类了解自然资 源的利用状况、评估区域发展可持续性提供了直观 和简洁的理论依据, 被称为 20 多年来可持续发展定 量研究领域最重要的进展之一 ${ }^{[6]}$ 。

经典生态足迹模型的关注重点是自然资本的 消费量和流量, 而非自然资本存量, 然而自然资本 存量在维持区域生态系统平衡以及可持续发展方 面起着关键性作用 ${ }^{\left[{ }^{[6]}\right.}$ 。因此, Niccolucci 等引人足迹
深度和足迹广度指标 ${ }^{[7,8]}$, 并提出三维生态足迹概 念, 以此来解释人类活动对资本流量和资本存量的 占用差异。近年来,国内外专家学者从理论和实践 两个方面围绕三维生态足迹进行了研究。在理论 层面,针对“不同地类生态赤字和盈余不可替代”、 “足迹深度在资本流量未耗尽时,无法表征资本流 量的占用程度” 等缺陷, 方恺等、靳相木等对模型进行 了改进或扩充 ${ }^{[9-11]}$ 。在实践层面, Niccolucci等分析了 1961-2006 年全球尺度上足迹深度和足迹广度的时 空变化特征 ${ }^{[7,8]}$ 。方恺等基于改进三维生态足迹模 型对全球 ${ }^{[12-14]}$ 、中国 ${ }^{[10]}$ 及各省 ${ }^{[15]}$ 的自然资本利用情况 进行了核算分析。杜悦悦等、周星星等分别以京津 冀和珠三角两大城市群为研究对象, 对比分析了城

收稿日期: 2016-12-26; 修订日期: 2017-03-09

基金项目: 国家自然科学基金项目 (41371535,41690142); 福建省科技计划项目引导性项目(2015Y0082)。

作者简介: 马维兢,男,宁夏同心人, 硕士生, 主要从事城市-区域系统地理生态过程与可持续性研究。E-mail: wjma@iue.ac.cn 通讯作者:杨德伟,E-mail:dwyang@iue.ac.cn; davecas@163.com 
市群内部不同城市间自然资本的利用状况 ${ }^{[16,17]}$ 。高 子铁等、秦超等分别对陕西省 1978-2011 年和 19832012 年间自然资本动态利用变化进行研究 ${ }^{[18,19]}$ 。靳 相木等通过改进模型，扩大足迹深度的取值范围， 对温州市不同土地类型的承载力指数进行研究 ${ }^{[1]}$ 。 秦超等、胡美娟等、刘超等、黄艳丽等以锡林郭勒 盟、南京市、张家口市、焦作市为研究对象, 通过自 然资本核算,分析了资本流量和资本存量的动态变 化趋势及驱动因子, 并对城市发展生态可持续性进 行了评价 ${ }^{[20-23]}$ 。总的来说, 三维生态足迹的研究覆 盖了全球、国家和省市尺度,但在流域尺度上的研 究还处于探索阶段。流域作为集政治、社会、经济、 生态、文化为一体的地理单元, 成为国际上进行可 持续发展评估、规划、实施不可或缺的重要载体。

近年来,伴随着中国经济社会发展以及海峡西 岸经济区建设, 九龙江流域城镇化、工业化进程加 快, 由此带来了建设用地增多、耕地面积减少、土地 利用不均衡、资源耗竭大以及环境污染等问题,流 域可持续发展面临严峻挑战。本文采用三维生态 足迹模型，通过对九龙江流域 2000 年、2005 年、 2010-2015 年的足迹广度、足迹深度以及三维生态 足迹进行核算与对比分析,揭示九龙江流域自然资 本流量和自然资本存量的利用状况与动态变化特 点,探讨评估流域经济社会发展过程中存在的问题 及生态可持续性, 以期为九龙江流域在城镇化、工 业化进程中的人口、资源、环境等相关政策的制定 提供科学依据。

\section{2 研究区概况}

九龙江位于中国东南沿海福建省境内, 全长 $285 \mathrm{~km}$, 是福建省的第二大河流, 由北溪、西溪和南 溪三大干流组成, 主要流经龙岩市、漳州市,在厦门 市人海。九龙江流域位置在 $116^{\circ} 46^{\prime} 55^{\prime \prime} \mathrm{E}-118^{\circ} 02^{\prime}$ $17^{\prime \prime} \mathrm{E}, 24^{\circ} 23^{\prime} 53^{\prime \prime} \mathrm{N}-25^{\circ} 53^{\prime} 38^{\prime \prime} \mathrm{N}$ 之间, 地势自西北向 东南倾斜,地貌类型以中、低山为主, 流域面积约为 1.47 万 $\mathrm{km}^{2}$, 占福建省陆域面积的 $12 \%$ 。 21 世纪以 来, 流域经济建设与城镇化进程步人快速发展阶 段,生态系统功能不断退化, 资源消耗速率不断增 长, 自然资本供给与需求矛盾日益突出。

本文选取九龙江流域内的 9 个主要区县 (漳州 市的芕城区、龙文区、龙海市、华安县、平和县、南靖
县和长泰县, 龙岩市的新罗区和漳平市) 作为研究 区域。2000-2015年,研究区域常住人口由 344 万增 加至 389 万, 人口城镇化率由 $22.8 \%$ 上升至 $61 \%$; 三 次产业结构由 $32.0: 31.4: 36.6$ 调整为 $13.4: 48.5$ : 38.1 , 人均国民生产总值 (GDP) 由 0.77 万元增加至 7.14 万元; 耕地比例由 $16.4 \%$ 下降至 $14.7 \%$, 林地比 例由 $65.1 \%$ 下降至 $63.5 \%$, 建设用地比例由 $2.0 \%$ 上 升至 $5.4 \%$ 。

\section{3 数据来源与研究方法}

\section{1 数据来源}

生态足迹模型中, 自然资源消费由生物资源消 费和能源消费两部分组成。研究区域生物资源消 费主要包括农产品、动物产品、林产品、水产品等, 能源消费主要有煤炭、焦炭、燃料油、汽油、柴油、液 化石油气、天然气等,这两部分数据主要来源于《福 建省统计年鉴》(2001年、2006年、2011-2016年) ${ }^{[24]}$ 。 土地利用数据通过遥感图像解译获得。计算过程 中生物资源初级产品全球平均产量及均衡因子采 用杨屹等研究结果 ${ }^{[25]}$, 产量因子、能源消费折算系数 参考郭秀锐等的文献 ${ }^{[26]}$ 。另外,计算化石能源用地 生态承载力时, 由于土地资源分类中没有化石能源 用地, 目前也没有专门的土地用于吸收能源消费过 程中排放的温室气体 ${ }^{[25,27]}$, 部分研究以零代替 ${ }^{[2]}$ 。 考虑到森林是主要的固碳用地 ${ }^{[27,28]}$, 与部分学者一 样 ${ }^{[11]}$, 本文选择用林地代替,但在计算区域足迹广度 时,为避免重复,没有计算在内。

\section{2 研究方法}

\subsection{1 三维生态足迹模型}

（1）基础三维模型。在生态足迹经典模型的基 础上, Niccolucci 等引人足迹深度和足迹广度, 用以 表征人类对自然资本存量和流量的利用水平。足 迹深度具有时间属性,表征人类对自然资本存量的 消耗程度, 其含义可以理解为满足区域发展, 需要 多少年才能再生人类一年中所消费的资源量; 足迹 广度具有空间属性,表征人类对自然资本流量的占 用程度, 表示区域生态承载力限度内实际占用的生 态生产性土地面积 ${ }^{[9,16]}$ 。新指标的引人不仅克服了 经典模型对资本存量重视不足的缺陷 ${ }^{\left[{ }^{[0]}\right.}$, 同时将生 态足迹模型由二维拓展为三维,形式上变成一个表 征体积的物理量 ${ }^{[8]}$ 。计算公式如下 ${ }^{[10]}$ : 


$$
\begin{aligned}
& E F_{\text {depth }}= \begin{cases}1+\frac{E F-E C}{E C} & E F>E C \\
1 & E F \leqslant E C\end{cases} \\
& E F_{\text {size }}= \begin{cases}E C & E F>E C \\
E F & E F \leqslant E C\end{cases} \\
& E F_{3 D}=E F_{\text {depth }} \times E F_{\text {size }}
\end{aligned}
$$

式中 $E F_{\text {depth }}$ 为足迹深度,无量纲, 等于 1 时表示自然 深度 ${ }^{[17]} ; E F_{\text {size }}$ 为足迹广度; $E F_{3 D}$ 为三维生态足迹; $E F$ 和 $E C$ 分别为经典模型中的生态足迹和生态承 载力。由公式可知: 足迹深度 $E F_{\text {depth }}$ 取值范围大于 等于 1 ,其值越大,表示人类对自然资本存量的需求 越大, 区域发展可持续性越弱; 足迹广度 $E F_{\text {size }}$ 取值 范围从 0 到 $E C$, 表示生态系统供给自然资本流量的 上限为生态承载力 (图 1)。

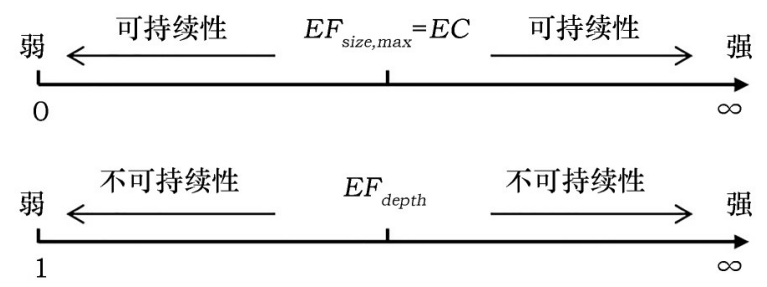

图 1 足迹广度与足迹深度的物理意义 ${ }^{[12]}$

Figure 1 Physical meanings of footprint size and footprint depth

(2)三维模型的改进。基础三维模型在计算某 一区域生态赤字时, 是基于区域总的生态足迹与生 态承载力相减,这种计算的缺陷是忽视了生态赤字 和生态盈余自然资本性质的差异 ${ }^{[3]}$, 结果可能出现 不同地类生态赤字和生态盈余相互抵消的情况, 最 终导致区域足迹深度偏小、足迹广度偏大。因此方 恺等提出基于不同地类生态赤字计算区域生态赤 字, 进而对区域三维生态足迹模型进行了改进 ${ }^{[0]}$ 。 计算公式为：

$$
\begin{aligned}
& E F_{\text {depth, region }}=1+\frac{\sum_{i=1}^{n} \max \left\{E F_{i}-E C_{i}, 0\right\}}{\sum_{i=1}^{n} E C_{i}} \\
& E F_{\text {size,region }}=\sum_{i=1}^{n} \min \left\{E F_{i}, E C_{i}\right\} \\
& E F_{3 D, \text { region }}=E F_{\text {depth,region }} \times E F_{\text {size,region }}
\end{aligned}
$$

式中 $E F_{3 D, \text { region }} 、 E F_{\text {depth,region }} 、 E F_{\text {size,region }}$ 分别代表区域 三维生态足迹、足迹深度和足迹广度; $i$ 为不同地类 生物生产性土地面积; $E F_{i} 、 E C_{i}$ 分别为第 $i$ 类土地 生态足迹和生态承载力。

\subsection{2 模型补充指标}

(1)资本流量占用率。为表征足迹深度处于自 然深度时, 人类活动对资本流量的实际占用程度， 引人资本流量占用率,计算公式为 ${ }^{[10]}$ :

$$
O R_{\text {flow }}=\frac{E F_{\text {size }}}{E C} \times 100 \% \quad(E F<E C)
$$

(2)存量流量利用比。当自然资本存量开始消 耗时, 为表征资本存量与资本流量之间的大小关 系,引人存量流量利用比,计算公式为 ${ }^{[10]}$ :

$$
R_{\text {flow }}^{\text {stock }}=\frac{E F-E F_{\text {size }}}{E F_{\text {size }}}=\frac{E D}{E C}=E F_{\text {depth }}-1(E F>E C)
$$

需要说明的是, 在基础三维模型中, 当 $E F$ 大于 $E C$ 时,表明资本流量消耗完,资本存量开始启用, 此时按照公式(8)计算存量流量利用比。但基于改 进三维模型计算时, 当区域 $E F$ 大于区域 $E C$ 时, 并 不意味着区域所有地类资本流量耗尽 (例如耕地资 本流量耗尽, 但林地资本流量可能有剩余), 即此时 可以计算区域资本流量占用率,但这与公式(7)的 条件矛盾。考虑到资本流量占用率的含义, 与他人 研究一样 ${ }^{[15]}$,仍然根据公式 (7)计算。

\subsection{3 变化率和剪刀差}

(1)变化率。为反映足迹深度、足迹广度随时 间变化的趋势和速度,引人多项式回归模型：

$$
\begin{aligned}
& E F_{\text {depth }}=E F_{\text {depth }}(t)=u_{0}+u_{1} t+u_{2} t^{2}+\cdots+u_{n} t^{n} \\
& E F_{\text {size }}=E F_{\text {size }}(t)=v_{0}+v_{1} t+v_{2} t^{2}+\cdots+v_{n} t^{n}
\end{aligned}
$$

式中自变量 $t$ 为时间, 对 $E F_{\text {depth }}(t)$ 和 $E F_{\text {size }}(t)$ 求导, 即 可得到 $t$ 时刻足迹深度和足迹广度变化率。本文中 令 2000 年时, $t=0 ; 2005$ 年时, $t=5$, 依此类推。

(2) 剪刀差。为反映某一年份足迹深度和足迹 广度变化趋势的差异,引人剪刀差模型：

$$
\alpha=\arccos \frac{1+E F_{\text {depth }}^{\prime}(t) \times E F_{\text {size }}{ }^{\prime}(t)}{\sqrt{1+\left(E F_{\text {depth }}^{\prime}(t)\right)^{2}} \times \sqrt{1+\left(E F_{\text {size }}^{\prime}(t)\right)^{2}}}
$$

式中 $E F_{\text {depth }}{ }^{\prime}(t)$ 和 $E F_{\text {size }}{ }^{\prime}(t)$ 为足迹深度和足迹广度在 $t$ 时刻的变化率; $\alpha$ 为二者的夹角,单位为弧度 $(\mathrm{rad})$, 表示足迹深度和足迹广度的剪刀差, $\alpha$ 越大, 说明 二者变化趋势之间的差异越大。

\section{4 结果分析}

\section{1 三维生态足迹分析}

4.1.1 足迹深度

根据公式(1)、公式(4)计算出流域不同地类和 
表 1 九龙江流域人均生态足迹深度

Table 1 Per capita ecological footprint depth in Jiulong River Basin

\begin{tabular}{cccccccc}
\hline 年份 & 耕地 & 林地 & 草地 & 水域 & 建设用地 & 化石能源 & 九龙江流域 \\
\hline 2000 & 3.14 & 1 & 1 & 1.44 & 1 & 2.07 & 2.34 \\
2005 & 3.52 & 1 & 1 & 1.54 & 1 & 3.00 & 2.86 \\
2010 & 3.45 & 1 & 1 & 1.73 & 1 & 4.51 & 3.46 \\
2011 & 3.59 & 1 & 1 & 1.61 & 1.06 & 5.02 & 3.72 \\
2012 & 4.18 & 1 & 1 & 1.72 & 1.11 & 5.00 & 3.94 \\
2013 & 4.57 & 1 & 1 & 1.78 & 1.19 & 5.16 & 4.16 \\
2014 & 4.56 & 1 & 1 & 1.98 & 1.25 & 5.51 & 4.33 \\
2015 & 4.66 & 1 & 1 & 2.23 & 1.25 & 5.41 & 4.33 \\
\hline
\end{tabular}

区域人均足迹深度 $($ 表 1)。2000-2015 年, 区域人均 足迹深度不断上升 (图 3), 由 2.34 增加至 4.33 , 平均 增速 $4.2 \%$, 说明区域发展对资源的需求越来越依赖 于自然资本存量。从不同地类来看,林地、草地足 迹深度始终处于自然深度,表明当地仅靠消耗这两 类用地的自然资本流量即可满足自身的发展需 求。建设用地足迹深度 2011 年之后大于 1 , 标志着 资本存量开始消耗, 资本流量已不能满足日益膨胀 的消费需求。耕地、水域和化石能源用地足迹深度 一直大于 1 , 且不断增加, 说明 2000 年以前就开始 消耗这三类用地的资本存量, 且消耗量越来越大; 另外,这三类用地是区域足迹深度增加的主要原 因,也是发展最不可持续的 ${ }^{[10,25]}$ 。

\subsection{2 足迹广度}

根据公式 (2)、公式 (5)计算出流域不同地类和 区域人均足迹广度 (表 2)。2000-2015 年, 区域人均 足迹广度由 $0.463 \mathrm{hm}^{2} /$ 人逐渐增加至 $0.655 \mathrm{hm}^{2} /$ 人, 表 明区域经济社会发展过程中,对资本流量的占用越 来越大。从不同地类来看,耕地、化石能源人均足 迹广度不断下降, 分别由 $0.362 \mathrm{hm}^{2} /$ 人、 $0.377 \mathrm{hm}^{2} /$ 人
减少至 $0.290 \mathrm{hm}^{2} /$ 人、 $0.327 \mathrm{hm}^{2} /$ 人, 表明这两类用地 资本流量的占用水平不断减弱; 草地、水域人均足 迹广度较小, 都经历了先增后减的过程, 表明草地、 水域资本流量的占用水平先升高后下降; 林地、建 设用地人均足迹广度逐渐增加, 分别由 $0.006 \mathrm{hm}^{2} /$ 人、 $0.013 \mathrm{hm}^{2} /$ 人增加至 $0.229 \mathrm{hm}^{2} /$ 人、 $0.042 \mathrm{hm}^{2} /$ 人,表 明这两类用地资本流量的占用水平越来越大。因 此, 区域足迹广度的增加并不代表区域生态承载力 上升,主要是因为林地、建设用地等资本流量的占 用水平提升。

4.1.3 生态足迹动态变化

(1)不同地类动态变化分析。根据公式(3)、公 式(6)计算出流域不同地类和区域人均三维生态足 迹(以下简称“三维足迹”)。如图 2 所示, 2000-2015 年,九龙江流域人均三维足迹总体上呈现出快速上 升的趋势, 由 $1.08 \mathrm{hm}^{2} /$ 人增加至 $2.84 \mathrm{hm}^{2} /$ 人, 平均增 速 $6.6 \%$ 。不同地类方面,耕地人均三维足迹呈现出 “增-减-增”的变化趋势, 总体上由 $1.14 \mathrm{hm}^{2} /$ 人增加至 $1.35 \mathrm{hm}^{2} /$ 人; 林地人均三维足迹持续快速上升, 由 $0.006 \mathrm{hm}^{2} /$ 人增长到 $0.229 \mathrm{hm}^{2} /$ 人, 增加了 37 倍, 平均

表 2 九龙江流域人均生态足迹广度

Table 2 Per capita ecological footprint size in Jiulong River Basin

$\left(\mathrm{hm}^{2} /\right.$ 人

\begin{tabular}{lllllccc}
\hline 年份 & 耕地 & 林地 & 草地 & 水域 & 建设用地 & 化石能源 & 九龙江流域 \\
\hline 2000 & 0.362 & 0.006 & 0.034 & 0.048 & 0.013 & 0.377 & 0.463 \\
2005 & 0.336 & 0.028 & 0.035 & 0.051 & 0.023 & 0.365 & 0.472 \\
2010 & 0.311 & 0.129 & 0.038 & 0.053 & 0.039 & 0.345 & 0.569 \\
2011 & 0.308 & 0.109 & 0.041 & 0.053 & 0.042 & 0.343 & 0.552 \\
2012 & 0.300 & 0.148 & 0.050 & 0.051 & 0.041 & 0.334 & 0.590 \\
2013 & 0.296 & 0.194 & 0.052 & 0.051 & 0.041 & 0.332 & 0.634 \\
2014 & 0.293 & 0.224 & 0.044 & 0.051 & 0.041 & 0.329 & 0.654 \\
2015 & 0.290 & 0.229 & 0.044 & 0.051 & 0.042 & 0.327 & 0.655 \\
\hline
\end{tabular}


增速 $27.5 \%$; 草地人均三维足迹很小, 变化趋势不明 显, 2015 年为 $0.044 \mathrm{hm}^{2} /$ 人; 水域人均三维足迹的变 化过程与耕地类似,同样呈现出“增-减-增”的变化 趋势, 总体上由 $0.069 \mathrm{hm}^{2} /$ 人增加至 $0.113 \mathrm{hm}^{2} /$ 人; 化 石能源用地人均三维足迹由 2000 年的 $0.403 \mathrm{hm}^{2} /$ 人 增加至 2011 年的 $1.38 \mathrm{hm}^{2} /$ 人, 平均增速 $11.8 \%$,近几 年增速放缓; 建设用地人均三维足迹由 $0.013 \mathrm{hm}^{2} /$ 人 增加至 $0.052 \mathrm{hm}^{2} /$ 人, 平均增速 $9.9 \%$ 。

(2)不同地类构成分析。由图3 可知,不同地类 对区域三维足迹的贡献率差异非常显著。20002015 年, 耕地贡献率快速减小, 由 $68.4 \%$ 下降至 $41.8 \%$; 林地贡献率逐渐增加, 由 $0.4 \%$ 上升至 $7.1 \%$; 草地贡献率变化不大,在 $1.3 \%$ 2.0\% 之间波动; 水域 贡献率先减小后增加, 总体上由 $4.2 \%$ 下降至 $3.5 \%$; 建设用地贡献率先增加后不变,由 2000 年的 $0.8 \%$ 上升至 2011 年的 $1.6 \%$,近几年不变; 化石能源用地

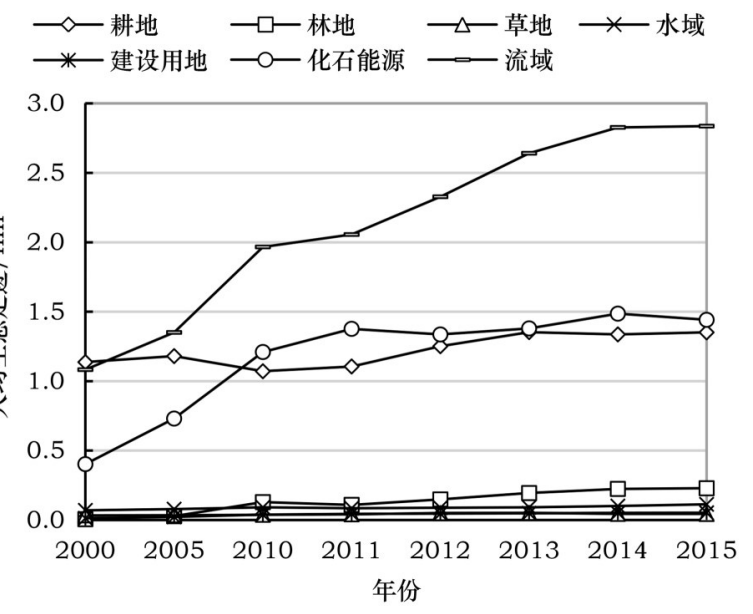

图 2 不同地类三维生态足迹动态变化

Figure 2 Different lands dynamic changes of $\mathrm{EF}_{3 \mathrm{D}}$
贡献率快速增加, 由 $24.2 \%$ 上升至 $44.6 \%$ 。总的来 说,耕地、草地、水域贡献率下降,林地、建设用地、 化石能源用地贡献率上升。结合图 4 可知, 各地类 三维足迹均未减小, 而贡献率结构发生了变化, 反 映出区域发展过程中对各种资源的需求均在增加, 但增长幅度存在差异。尤其是化石能源用地三维 足迹的增加, 是贡献率结构改变的最主要原因,推 动了区域三维足迹的上升, 说明区域城镇化与工业 化进程中,化石能源消费量快速增加 ${ }^{[25]}$ 。

(3) 三维生态足迹图形对比。根据三维模型概 念, 可以将九龙江流域生态足迹视为一个体积逐渐 增加的圆柱体。如图 4所示, 2000-2015 年, 圆柱体 的底面积 (足迹广度) 和高 (足迹深度)都在不断增 加。底面积增加是区域资本流量利用不断增加的 反映, 高增加是区域资本存量消耗不断上升的反 映。二者的同向变化趋势, 导致三维生态足迹不断

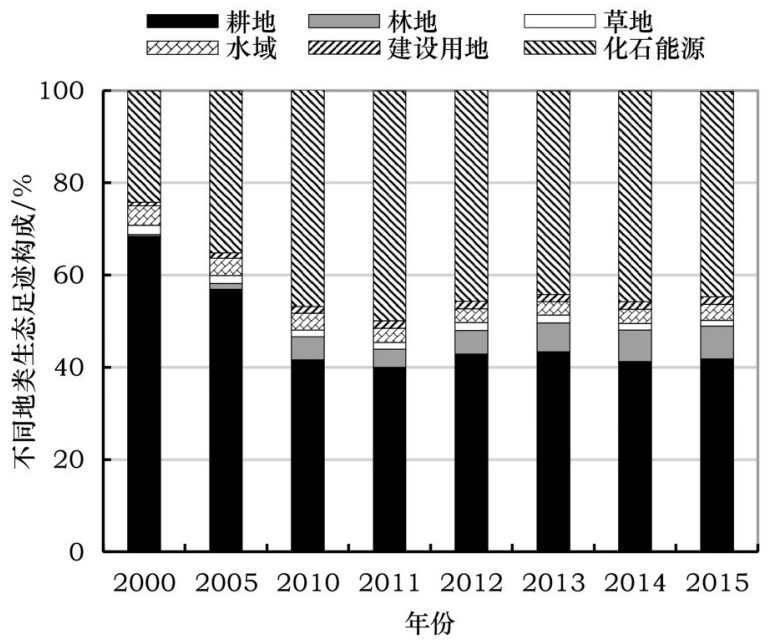

图 3 不同地类三维生态足迹构成

Figure 3 Different lands components of $\mathrm{EF}_{3 \mathrm{D}}$

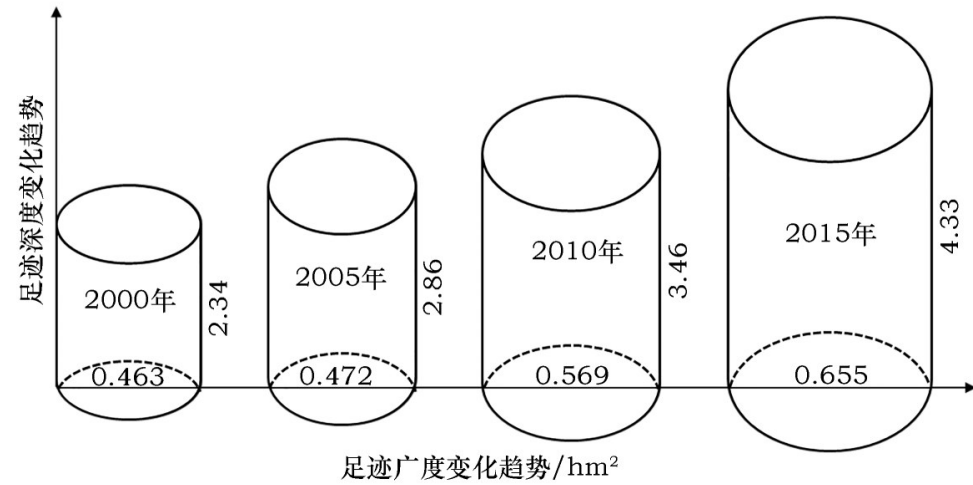

图 4 九龙江流域三维生态足迹动态变化

Figure 4 3D ecological footprint dynamic changes in Jiulong River Basin 
增加, 区域生态系统供给服务压力越来越大。

\section{2 资本流量占用率与存量流量利用比分析}

根据公式 (7)、公式 (8)计算可得九龙江流域资 本流量占用率与存量流量利用比（表3)。20002015 年, 区域资本流量占用率快速上升,由 $51.7 \%$ 增 加至 $84.7 \%$ 。从不同地类来看,耕地存量流量利用 比由 2.14 增加至 3.66 ,增速 $3.7 \%$; 化石能源用地存 量流量利用比由 1.07 增加至 4.41 , 增速 $9.9 \%$; 水域 存量流量利用比由 0.44 增加至 1.23 ,增速 $7.1 \%$; 林 地、草地资源的资本存量一直没有启用, 但资本流 量占用率均在不断上升,分别由 $1.6 \%$ 和 $45.6 \%$ 增加 至 $70 \%$ 和 $68.4 \%$; 建设用地资本存量的启用始于 2011 年, 存量流量利用比 2015 年时达到 0.25 。总的 来说, 林地、草地资本流量占用率提高导致区域资 本流量占用水平快速上升; 耕地、水域、化石能源用 地资本存量的消耗是区域资本存量消耗的主要原 因, 尤其是化石能源用地消耗量增加, 大幅提高了 流域资本存量消耗的速度; 建设用地存量流量利用 比目前较小,但仍然显示资本流量已不能满足区域 发展的需要,资本存量消耗逐渐增加。

\section{3 足迹深度和足迹广度变化趋势分析}

\subsection{1 变化率}

根据公式(9)、公式(10), 计算得到足迹深度和 足迹广度的变化率曲线(图 5、图 6)。2005-2015 年, 流域足迹深度、足迹广度变化率逐渐增大, 分别由 $10.52 \%$ 和 $0.17 \%$ 上升至 $13.30 \%$ 和 $1.28 \%$, 显示出 21 世纪以来流域发展过程中自然资本存量的消耗速 度越来越快, 资本流量的占用越来越多, 二者的同 向变化, 表明区域生态足迹增速不断加快。从不同 地类来看,耕地足迹深度变化率在 $7.55 \%$ 10.18\% 之
间,波动较大, 总体上处于增加的态势, 足迹广度在 $-0.53 \%$ 与 $-0.48 \%$ 之间, 波动较小, 表明耕地资本存量 消耗越来越快, 资本流量占用减小幅度不大; 林地、 草地足迹深度变化率始终为零, 这是因为二者足迹 深度始终为 1 , 但林地足迹广度由 $0.43 \%$ 增加至 $1.49 \%$, 且与区域足迹广度变化趋势基本一致,说明 林地资本流量的占用率决定了区域足迹广度的占 用率, 草地足迹广度维持在 $0.02 \% \sim 0.14 \%$ 之间 ; 水域 足迹深度变化率在 $2.06 \%$ $5.26 \%$ 之间波动上升, 足 迹广度变化率略大于零; 建设用地足迹深度变化率 2011 年开始大于零, 足迹广度变化率与水域相似; 化石能源用地足迹深度变化率先增后减,在 $18.73 \%$ $26.84 \%$ 之间波动，足迹广度变化率由 $-0.25 \%$ 下降 至 $-0.33 \%$, 表明化石能源用地足迹深度始终处于高 速增加的状态，足迹广度的占用越来越小，二者的 反向变化趋势意味着化石能源用地生态赤字越来 越大。

\subsection{2 剪刀差}

根据公式(9)、公式(10)、公式(11)计算得到足 迹深度和足迹广度的剪刀差(表4)。2005-2015年， 流域足迹深度和足迹广度的变化差异越来越大, 由 1.167 增加至 1.343 , 反映了资本存量的消耗不仅在 加速上升,而且加速度越来越大。不同地类方面, 耕地、化石能源用地剪刀差最大, 水域用地剪刀差 次之,但均逐渐上升, 反映出区域发展过程中这几 类用地最为紧缺, 自然资本存量消耗的依赖性越来 越强; 林地、草地、建设用地的剪刀差相对较小, 且 维持稳定, 主要是因为这三类用地足迹深度一直保 持不变(建设用地 2011 年之前不变),剪刀差主要取 决于足迹广度的变化。

表 3 资本流量占用率和存量流量利用比

Table 3 Appropriation rate of capital flows and use ratio of stocks to flows in Jiulong River Basin

\begin{tabular}{lllllccc}
\hline 年份 & 耕地 & 林地 & 草地 & 水域 & 建设用地 & 化石能源 & 九龙江流域 \\
\hline 2000 & 2.14 & $1.6 \%$ & $45.6 \%$ & 0.44 & $37.8 \%$ & 1.07 & $51.7 \%$ \\
2005 & 2.52 & $7.6 \%$ & $48.8 \%$ & 0.54 & $61.1 \%$ & 2.00 & $54.9 \%$ \\
2010 & 2.45 & $37.3 \%$ & $56.0 \%$ & 0.73 & $92.7 \%$ & 3.51 & $69.6 \%$ \\
2011 & 2.59 & $31.8 \%$ & $61.7 \%$ & 0.61 & 0.06 & 4.02 & $68.1 \%$ \\
2012 & 3.18 & $44.4 \%$ & $76.5 \%$ & 0.72 & 0.11 & 4.00 & $74.6 \%$ \\
2013 & 3.57 & $58.5 \%$ & $79.4 \%$ & 0.78 & 0.19 & 4.16 & $80.8 \%$ \\
2014 & 3.56 & $68.0 \%$ & $69.1 \%$ & 0.98 & 0.25 & 4.51 & $83.9 \%$ \\
2015 & 3.66 & $70.0 \%$ & $68.4 \%$ & 1.23 & 0.25 & 4.41 & $84.7 \%$ \\
\hline 注: “\%”数据代表资本流量占用率,其他数据代表存量流量利用比 &
\end{tabular}




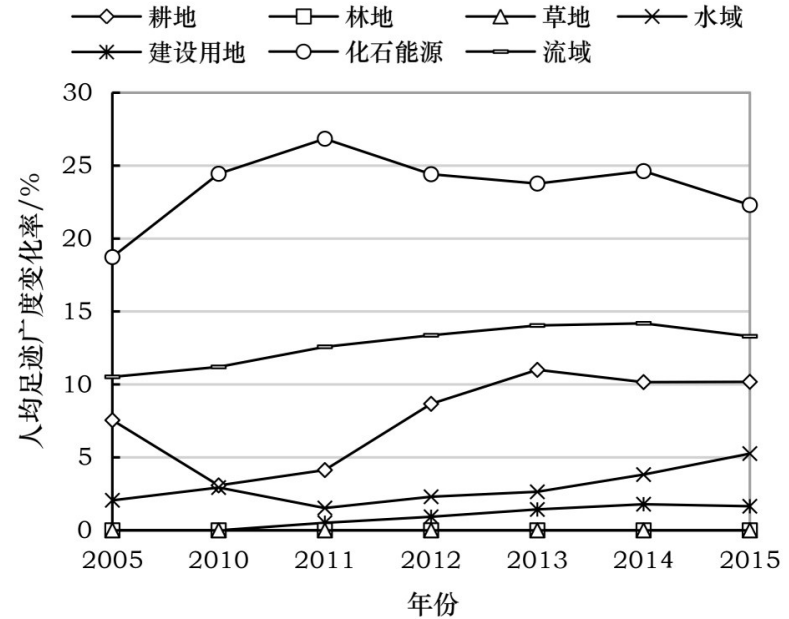

图 5 不同地类足迹深度变化率

Figure 5 Footprint depth change rate of different lands

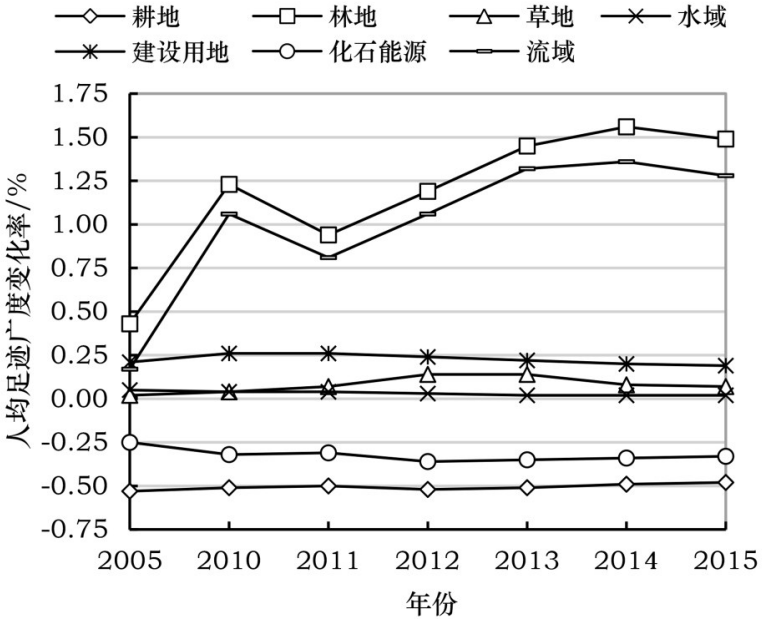

图 6 不同地类足迹广度变化率

Figure 6 Footprint size change rate of different lands

表 4 足迹深度和足迹广度剪刀差

Table 4 Scissors difference between footprint depth and footprint size

\begin{tabular}{cccccccc}
\hline 年份 & 耕地 & 林地 & 草地 & 水域 & 建设用地 & 化石能源 & 九龙江流域 \\
\hline 2005 & 1.262 & 0.785 & 0.785 & 0.964 & 0.785 & 1.120 & 1.167 \\
2010 & 1.294 & 0.785 & 0.785 & 0.996 & 0.785 & 1.250 & 1.235 \\
2011 & 1.288 & 0.785 & 0.785 & 1.048 & 0.785 & 1.353 & 1.289 \\
2012 & 1.299 & 0.785 & 0.785 & 1.015 & 0.813 & 1.374 & 1.308 \\
2013 & 1.336 & 0.786 & 0.785 & 1.044 & 0.838 & 1.373 & 1.322 \\
2014 & 1.355 & 0.786 & 0.785 & 1.060 & 0.870 & 1.379 & 1.335 \\
2015 & 1.355 & 0.786 & 0.785 & 1.102 & 0.896 & 1.392 & 1.343 \\
\hline
\end{tabular}

\section{5 讨论与结论}

\section{1 讨论}

人口增长、城镇化与工业化进程加快往往是区 域生态足迹增加的主要驱动因素 ${ }^{[17]}$ 。2000-2015 年, 研究区域常住人口增加 45 万, 城镇人口比例上升了 $38.2 \%$, 城镇化过程中居民消费结构升级 ${ }^{[22]}$, 资源消 费量增加等, 加剧了流域生态系统供给服务的压 力。流域生物资源账户 (耕地、林地、草地、水域)用 地需求不断扩大, 导致生物资源账户足迹广度、足 迹深度不断上升, 最终使得生态足迹不断增加。同 时,城镇化进程下的工业化以高耗能产业的高速发 展为特征,在化石能源为主要能源的背景下,城镇 化进程推动了化石能源的消费, 导致化石能源生态 足迹上升速度最快, 进一步推动了流域生态足迹的 加速增长。另外,城镇化、工业化进程中, 建设用地 规模不断扩张, 这虽然使其足迹广度逐渐增加, 但 仍然无法满足区域发展, 2011 年时资本存量开始消
耗,存量流量利用比不断扩大。

在资源利用水平未能提高的情况下,经济越发 达, 生态足迹越高 ${ }^{[17,33]}$ 。2000-2015 年, 九龙江流域 人均 GDP 由 7732 元增加至 71409 元, 经济的快速 增长导致自然资本产品和服务的大量消耗。同时, 国民生产总值中三次产业结构, 反映了自然资本的 利用方式, 影响着区域足迹深度、足迹广度及生态 足迹的变化趋势, 尤其是第二产业 ${ }^{[17]}$ 。研究期内第 二产业比重由 $31.4 \%$ 上升至 $48.5 \%$, 直接导致化石 能源消费用地的增加，同时排放出大量的温室气 体。化石能源用地存量流量利用比扩大至 4.41 , 说 明即便是所有林地都用来吸收二氧化碳, 仍然不足 以抵消区域的碳排放量。

土地资源禀赋决定了自然资本的利用方式, 是 区域社会经济可持续发展的重要保障 ${ }^{[23]}$ 。20002015 年, 流域耕地面积由 24.07 万 $\mathrm{hm}^{2}$ 下降至 21.73 万 $\mathrm{hm}^{2}$, 随着流域人口的增加, 人均耕地资本流量逐 
渐减小, 资本存量不断攀升, 存量流量利用比不断 扩大。林地、草地面积由 118.93 万 $\mathrm{hm}^{2}$ 减少至 116.13 万 $\mathrm{hm}^{2}$, 只减少了 2.80 万 $\mathrm{hm}^{2}$, 是流域内最丰 富的土地资源, 因此自然资本的利用一直依赖于资 本流量。水域面积由 1.01 万 $\mathrm{hm}^{2}$ 增加至 1.19 万 $\mathrm{hm}^{2}$, 尽管增加了 0.18 万 $\mathrm{hm}^{2}$, 足迹广度有所变大, 但 由于人口增加以及水产品的需求量随着人民生活 水平的上升而增加等原因, 导致水域用地足迹深 度、存量流量利用比仍然逐渐增大。建设用地面积 由 2.87 万 $\mathrm{hm}^{2}$ 增加至 8 万 $\mathrm{hm}^{2}$, 年均增加 0.33 万 $\mathrm{hm}^{2}$, 尽管建设用地的资本流量增加了,但以牺牲其它地 类面积作为代价, 尤其是耕地,加快了耕地资本流 量的减少速度。

\section{2 结论}

本文基于三维生态足迹模型及其相应指标, 评 估了 2000-2015 年九龙江流域人均足迹广度、人均 足迹深度及三维生态足迹,并对不同地类之间的差 异进行了详细分析,研究发现:

(1) 九龙江流域资本流量占用逐渐增大, 资本 存量消耗加速上升, 区域可持续发展面临的挑战日 益严峻。九龙江流域人均足迹深度由 2.34 快速上 升增加至 4.33 , 表明满足区域发展的自然资本消费 需求扩大为原来的 1.85 倍,生态系统供给服务压力 在持续快速增加。足迹广度由 $0.463 \mathrm{hm}^{2} /$ 人逐渐增 加至 $0.655 \mathrm{hm}^{2} /$ 人, 资本流量占用率由 $51.7 \%$ 增加至 $84.7 \%$, 表明区域资本流量的占用水平在不断攀升; 三维生态足迹由 $1.08 \mathrm{hm}^{2} /$ 人增加至 $2.84 \mathrm{hm}^{2} /$ 人, 在生 态承载力逐渐减小的情况下, 表明区域生态赤字越 来越大。

(2)不同地类自然资本利用差异显著。耕地、 水域、建设用地、化石能源用地人均足迹深度、存量 流量利用比越来越大, 表明这几类用地处于生态赤 字状态, 自然资本流量不能满足区域发展的需要。 其中, 化石能源用地需求增加最快, 是区域生态足 迹不同地类贡献率结构改变和生态足迹加速上升 的最主要原因; 林地、草地足迹深度一直处于自然 深度, 但足迹广度、资本流量占用率快速增加, 表明 区域发展目前还不需要消耗这两类用地的资本存 量,但资本流量占用程度越来越高。

(3)促进流域可持续发展,需要尽可能增加资
本流量、减少资本存量消耗, 从而拓宽足迹广度的 取值范围, 降低足迹深度。为此, 需要加大耕地资 源保护力度,科学规划建设用地规模; 优化工业企 业能源结构, 提高能源利用效率; 加强生态环境保 护宣传,倡导节约型消费等。

\section{参考文献 (References)：}

[ 1 ] 贺锡苹, 张小华. 耕地资产核算方法与实例分析 [J]. 中国土地 科学, 1994, (6) : 23-27. [He X P, Zhang X H. Accounting method and example analysis of cultivated land assets[J]. China Land Science, 1994, (6):23-27.]

[2] 高兴佑,郭昀. 可持续发展观下的自然资源价格构成研究 [J]. 资源与产业,2010,12(2) : 129-133. [Gao X Y, Guo Y. Study on price structure of natural resources from the point of view of sustainable development[J]. Resources \& Industries, 2010, 12 (2) : 129-133.

[ 3 ] Hambira W L. Natural resources accounting: A tool for wate resources management in Botswana[J]. Physics \& Chemistry of the Earth Parts A/b/c, 2007,32 (15-18) : 1310-1314.

[4] Harris M, Fraser I. Natural resource accounting in theory and practice: A critical assessment[J]. Australian Journal of Agricultural and Resource Economics, 2002,46(2): 139-192.

[5] Rees W E. Ecological footprints and appropriated carrying capacity: What urban economics leaves out[J]. Environment \& Urbanization, 1992,4(2):121-130.

[6] 徐中民,程国栋, 张志强. 生态足迹方法的理论解析[J]. 中国人 口・资源与环境, 2006, 16(6) : 69-78. [Xu Z M, Cheng G D, Zhang Z Q. A resolution to the conception of ecological footprint [J]. China Population, Resources and Environment, 2006, 16 (6) :69-78.]

[7] Niccolucci V, Bastianoni S, Tiezzi E B P, et al. How deep is the footprint? A 3D representation[J]. Ecological Modelling, 2009, $220(20): 2819-2823$

[8] Niccolucci V, Galli A, Reed A, et al. Towards a 3D national ecological footprint geography[J]. Ecological Modelling, 2011, 222(16): 2939-2944.

[9] 方恺, Reinout H. 自然资本核算的生态足迹三维模型研究进展 [J]. 地理科学进展, 2012,31 (12): 1700-1707. [Fang K, Reinout $\mathrm{H}$. A review on three-dimensional ecological footprint model for natural capital accounting[J]. Progress in Geography, 2012, 31 (12):1700-1707.]

[10] 方恺. 生态足迹深度和广度: 构建三维模型的新指标 $[\mathrm{J}]$. 生态 学报, 2013, 33 (1) : 267-274. [Fang K. Ecological footprint depth and size: New indicators for a 3D model[J]. Acta Eco- 
logica Sinica ,2013,33(1):267-274.]

[11] 靳相木, 柳乾坤. 基于三维生态足迹模型扩展的土地承载力指 数研究-以温州市为例 [J]. 生态学报, 2017,37(9) : 1-12. [Jin X M, Liu Q K. Analysis of a land carrying capacity index based on an expanded three- dimensional ecological footprint model: A case study of Wenzhou[J]. Acta Ecologica Sinica, 2017,37(9): 1-12.]

[12] 方恺, 高凯,李焕承. 基于三维生态足迹模型优化的自然资本 利用国际比较[J]. 地理研究, 2013,32(9): 1657-1667. [Fang K, Gao K, Li H C, et al. International comparison of natural capital use: A three- dimensional model optimization of ecological footprint[J]. Geographical Research, 2013,32(9) : 1657-1667.]

[13] 方恺. 1999-2008 年 G20 国家自然资本利用的空间格局变化 [J]. 资源科学, 2014, 36(4) : 793-800. [Fang K. Changes in the spatial distribution of natural capital use among G20 countries from 1999 to 2008[J]. Resources Science, 2014,36(4) :793-800.]

[14] 方恺. 基于改进生态足迹三维模型的自然资本利用特征分析选取 11 个国家为数据源 [J]. 生态学报, 2015,35(11):37663777. [Fang K. Assessing the natural capital use of major nations: An application of a revised three-dimensional model of ecological footprint[J]. Acta Ecologica Sinica, 2015, 35 (11) : 3766-3777.]

[15] 方恺, 李焕承. 基于生态足迹深度和广度的中国自然资本利用 省际格局 [J]. 自然资源学报, 2012,27(12): 1995-2005. [Fang K, Li H C. Provincial pattern of China's natural capital use: A modification and application of ecological footprint depth and size[J]. Journal of Natural Resources ,2012,27(12) : 1995-2005.]

[16] 杜悦悦,彭建,高阳,等. 基于三维生态足迹的京津冀城市群自 然资本可持续利用分析 $[\mathrm{J}]$. 地理科学进展, 2016, 35 (10): 1186- 1196. [Du Y Y, Peng J, Gao Y, et al. Sustainability evaluation of natural capital utilization based on a threedimensional ecological footprint model: A case study of the Beijing-Tianjin-Hebei Metropolitan region[J]. Progress in Geography, 2016,35(10):1186-1196.]

[17] 张星星, 曾辉. 珠江三角洲城市群三维生态足迹动态变化及驱 动力分析 $[J]$. 环境科学学报, 2017,37(2):771-778. [Zhang X $\mathrm{X}$, Zeng H. Dynamic of three dimensional ecological footprint in the Peral River Delta and its driving factors[J]. Acta Scientiae Circumatantiae, 2017,37(2):771-778.]

[18] 高子轶,李晶. 陕西省自然资本核算的三维生态足迹模型应用 研究 $[J]$. 陕西师范大学学报 (自科版), 2014, 42 (5): 79-83 [Gao Z T, Li J. Application of the new 3D ecological footprint model in natural capital accounting of Shaanxi Province $[\mathrm{J}]$. Journal of Shaanxi Normal University, 2014,42( 5 ) : 79-83.]

[19] 秦超,李君轶,陈宏飞,等. 基于三维生态足迹的陕西省自然资 本动态研究 [J]. 干旱区研究, 2016,33(4) : 837-842. [Qin C, Li J Y, Chen H F, et al. Dynamics of natural capital in Shaanxi
Province based on the three-dimensional ecological footprint $[\mathrm{J}]$. Arid Zone Research, 2016,33(4) : 837-842.]

[20］秦超,李君轶, 陈宏飞. 基于三维生态足迹的锡林郭勒盟自然 资本动态研究 $[\mathrm{J}]$. 干旱区资源与环境, 2015,29(9) : 51-56. [Qin C, Li J Y, Chen H F. Dynamic analysis of natural capital in Xilinguole League based on the three-dimensional ecological footprint[J]. Journal of Arid Land Resources and Environment, 2015,29(9):51-56.]

[21] 胡美娟, 周年兴, 李在军, 等. 南京市三维生态足迹测算及驱动 因子 $[\mathrm{J}]$. 地理与地理信息科学, 2015,31 (1) : 91-95. [Hu M J, Zhou N X, Li Z J, et al. Calculation and driving factor analysis of three- dimensional ecological footprint in Nanjing City[J]. Geography and Geo-information Science, 2015,31 (1) :91-95.]

[22] 刘超,许月卿,孙不苓, 等. 基于改进三维生态足迹模型的张家 口市生态可持续性评价 [J]. 水土保持通报, 2016,36(6) : 169176. [Liu C, Xu Y Q, Sun P L, et al. [Evaluation of ecological sustainability based on revised three- dimensional model of ecological footprint in Zhangjiakou City[J]. Bulletin of Soil and Water Conservation, 2016,36(6) : 169-176.]

[23] 黄艳丽,乔卫芳. 焦作市人均三维生态足迹的动态分析 $[\mathrm{J}]$. 资 源开发与市场, 2017, 33(2): 156-173. [Huang Y L, Qiao W F. Dynamic analysis of per capita three- dimensional ecological footprint in Jiaozuo City[J]. Resource Development \& Market, 2017,33(2):156-173.]

[24] 福建省统计局. 福建省统计年鉴(2001, 2006, 2011-2016)[M]. 北京: 中国统计出版社, 2001, 2006, 2011-2016. [Fujian Province Bureau of Statistics. Fujian Statistical Yearbook(2001, 2006, 2011-2016) [M]. Beijing: China Statistics Press, 2001 2006,2011-2016.]

[25] 杨屹,加涛. 21 世纪以来陕西生态足迹和承载力变化 $[\mathrm{J}]$. 生态 学报, 2015, 35 (24): 7987- 7997. [Yang Y, Jia T. The 21st century ecological carrying capacity and footprint in Shaanxi Province[J]. Acta Ecologica Sinica ,2015,35(24) : 7987-7997.]

[26] 郭秀锐,杨居荣, 毛显强. 城市生态足迹计算与分析-以广州为 例 [J]. 地理研究, 2003,22(5) : 654-662. [Guo X R, Yang J R, Mao X Q. Calculation and analysis of urban ecological footprint: A case study of Guangzhou[J]. Geographical Research, 2003, 22 (5) : 654-662.]

[27] 方恺,沈万斌,郑沁敏, 等. 化石能源地生态承载力研究 [J]. 环 境科学与技术, 2011,34(12): 201-205. [Fang K, Shen W B, Zheng Q M, et al. Ecological carrying capacity of fossil energy land[J]. Environmental Science \& Technology, 2011, 34 (12) : 201-205.]

[28] 谢鸿宇, 陈贤生, 林凯荣, 等. 基于碳循环的化石能源及电力生 态足迹[J]. 生态学报, 2008,28(4): 1729-1735. [Xie H Y, Chen $\mathrm{X} \mathrm{S}$, Lin K R, et al. The ecological footprint analysis of fossil energy and electricity[J]. Acta Ecologica Sinica, 2008, 28 (4) : 
1729-1735.]

[29] 赵荣钦,黄贤金. 基于能源消费的江苏省土地利用碳排放与碳 足迹 [J]. 地理研究, 2010,29(9): 1639-1649. [Zhao R Q, Huang $\mathrm{X}$ J. Carbon emission and carbon footprint of different land use types based on energy consumption of Jiangsu Province[J] Geographical Research,2010,29(9):1639-1649.]

[30] 甄霖,魏云洁,谢高地,等. 中国土地利用多功能性动态的区域 分析 [J]. 生态学报, 2010,30(24):6749-6761. [Lin Z, Wei Y J, Xie G D, et al. Regional analysis of dynamic land use functions in China[J]. Acta Ecologica Sinica, 2010,30(24) : 6749-6761.]

[31] 靳相木, 柳乾坤. 自然资源核算的生态足迹模型演进及其评论 [J]. 自然资源学报, 2017,32(1) : 163-176. [Jin X M, Liu Q K.
Evolution of ecological footprint model based on natural resources accounting[J]. Journal of Natural Resources, 2017, 32 (1): 163-176.]

[32] 彭希哲,刘宇辉. 生态足迹与区域生态适度人口-以西部 12 省 市为例 [J]. 人口与发展, 2004, 10(4): 9-15. [Peng X Z, Liu Y H. Ecological footprint and regional eco-optimum population: Take China's western provinces as an example[J]. Market \& Demographic Analysis, 2004,10(4):9-15.]

[33] Rees W, Wackernagel M. Urban ecological footprints: Why cities cannot be sustainable- and why they are a key to sustainability[J]. Environmental Impact Assessment Review, 1996, 16(4-6) :223-248.

\title{
Dynamic evaluation of natural capital using the Three-Dimension Ecological Footprint Model : the Jiulong River Basin in Southeast China
}

\author{
MA Weijing ${ }^{1,2,3}$, LIU Bin ${ }^{1,2,3}$, YANG Dewei ${ }^{1,3}$, GUO Qinghai ${ }^{1,3}$ \\ (1. Key Lab of Urban Environment and Health, Institute of Urban Environment, Chinese Academy of Sciences, Xiamen 361021, China; \\ 2. University of Chinese Academy of Sciences, Beijing 100049, China; 3. Xiamen Key Lab of Urban Metabolism, Xiamen 361021, China)
}

\begin{abstract}
Natural capital assessment is an important way to analyze the regional ecosystem balance and sustainable development. Based on the Three- Dimensional Ecological Footprint Model, the per capita footprint depth, footprint size and three-dimensional ecological footprint from 2000 to 2015 were calculated for regional and different land types in the Jiulong River Basin, southeast China. We analyzed the occupation of regional natural capital flow and natural capital stocks, and differences among different land types using the capital flow occupancy rate, use ratio of stocks to flows and other indices. We found that in the Jiulong River Basin, the per capita footprint depth increased from 2.34 to 4.33 , the per capita footprint size increased from $0.463 \mathrm{hm}^{2}$ to $0.655 \mathrm{hm}^{2}$, and the per capita three-dimensional ecological footprint expanded from $1.08 \mathrm{hm}^{2}$ to $2.84 \mathrm{hm}^{2}$. This means that the occupation level of regional natural capital flows gradually increased, the consumption of natural capital stocks rapidly increased, and thus resulted in the more intensive pressure on ecosystem services. Significant differences lie in the use of natural capital in different land types. All land types but forest and grassland performed were in ecological deficit from 2011. Increased demand on fossil energy land was the fastest and led to accelerated increase in the regional ecological footprint. Increasing natural capital flows and reducing the consumption of natural capital stocks are urgently required in order to achieve regional sustainability. More measures are encouraged to regulate construction land scale, protect limited cultivated land, improve energy use efficiency and promote conservation-oriented consumption.
\end{abstract}

Key words : ecological footprint; Three-Dimensional Model ; natural capital ; sustainability; Jiulong River Basin 